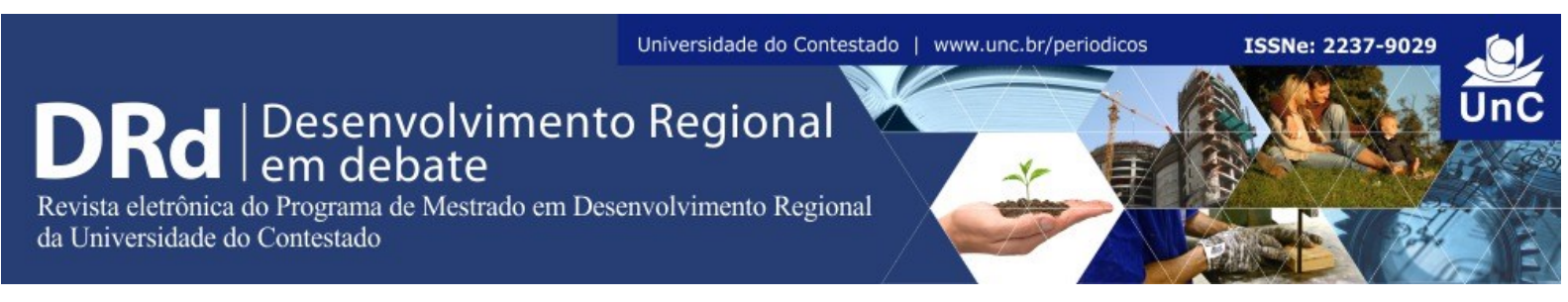

\title{
DINÂMICA LOCACIONAL DA ESTRUTURA PRODUTIVA NAS MESORREGIÕES DO CEARÁ NOS ANOS DE 2005 E 2015
}

\author{
Natanael Pessoa Lustoza ${ }^{1}$ \\ Denis Fernandes Alves ${ }^{2}$ \\ Francisco do O' de Lima Júnior ${ }^{3}$
}

\begin{abstract}
RESUMO
Este trabalho teve como objetivo geral estudar a dinâmica locacional das atividades econômicas no Estado do Ceará a partir de suas mesorregiões, nos anos de 2005 e 2015. Para tanto, os dados básicos utilizados para a construção dos indicadores referem-se aos empregos formais classificados por setores entre as mesorregiões do estado do Ceará, obtidos na Relação Anual de Informações Sociais (RAIS), mantido pelo Ministério do Trabalho e Emprego (MTE). Os principais resultados apontaram a mesorregião do Jaguaribe como mais especializada no ramo agropecuário tanto em $2005(8,43)$ quanto $2015(9,71)$ demonstrando a influência da modernização agrícola nesta região. A mesorregião Metropolitana de Fortaleza apresentou desempenho significativo no setor de Comércio e Construção Civil, em ambos anos analisados, demonstrando especialização no setor. Embora tenha diminuído a concentração no setor industrial da mesorregião, cabe destacar que essa reorientação espacial na Indústria foi destinada a municípios que compõe a Região Metropolitana de Fortaleza, reafirmando, assim, a apropriação espacial pela reestruturação produtiva. Os setores de serviços e comércio apresentaram um alto grau de especialização e foram os mais significativos entre as mesorregiões cearenses nos anos analisados. Por outro lado, o setor de Construção Civil está concentrado nas mesorregiões Metropolitana de Fortaleza $(1,19)$ e Norte Cearense (1,02), no ano de 2015.
\end{abstract}

Palavras-chave: Dinâmica Locacional. Mesorregiões Cearenses. Desenvolvimento Regional.

\footnotetext{
${ }^{1}$ Graduado em economia pela Universidade Regional do Cariri (URCA). Universidade Regional do Cariri (URCA). Ceará. Brasil. E-mail: natanaelpessoa1995@gmail.com

${ }^{2}$ Graduado em Economia pela Universidade Regional do Cariri (URCA). Mestre em Economia pelo Programa de Pós-graduação em Economia da Universidade Federal do Rio Grande do Norte. Natal, Rio Grande do Norte. Brasil. E-mail: denis fernandes@outlook.com

${ }^{3}$ Doutor em Desenvolvimento Econômico, Professor Associado do Departamento de Economia da URCA e do Programa de Pós-graduação em Planejamento e Dinâmicas Territoriais do Semiárido, na Universidade Estadual do Rio Grande do Norte. Crato, Ceará. Brasil. E-mail.: limajunior economia@yahoo.com.br
}

DRd - Desenvolvimento Regional em debate (ISSNe 2237-9029)

v. 9, p. 77-93, 2019. 


\title{
LOCATIONAL DYNAMICS OF THE PRODUCTIVE STRUCTURE IN THE CEARÁ MESORREGIÕES IN THE YEARS OF 2005 AND 2015
}

\begin{abstract}
The main objective of this study was to study the locational dynamics of economic activities in the State of Ceará from their mesoregions in 2005 and 2015. The basic data used for the construction of the indicators refer to the formal jobs classified by between the mesoregions of the state of Ceará, obtained from the Annual Social Information Report (RAIS), maintained by the Ministry of Labor and Employment (MTE). The main results pointed to the Jaguaribe mesoregion as more specialized in the agricultural sector both in 2005 (8.43) and 2015 (9.71), demonstrating the influence of agricultural modernization in this region. The metropolitan mesoregion of Fortaleza presented significant performance in the sector of Trade and Civil Construction, in both years analyzed, demonstrating specialization in the sector. Although the concentration in the industrial sector of the mesoregion has diminished, it should be noted that this spatial reorientation in the industry was destined to the municipalities that compose the Metropolitan Region of Fortaleza, thus reaffirming the spatial appropriation by the productive restructuring. The services and commerce sectors presented a high degree of specialization and were the most significant among the mesoregions of Ceará in the analyzed years. On the other hand, the Civil Construction sector is concentrated in the metropolitan regions of Fortaleza (1.19) and North Ceará (1.02), in the year 2015.
\end{abstract}

Keywords: Locational dynamic. Meso-regions of Ceará. Regional development; Region.

\section{INTRODUÇÃO}

O desenvolvimento regional é destaque nas discussões das organizações e instituições, principalmente pela sua importância nas transformações econômicas, políticas, humanas e sociais, sejam locais, regionais ou nacionais. Há grande preocupação dos agentes, que fazem parte desse processo de mudanças, compreender e analisar o desenvolvimento (RAMOS et al., 2017).

A questão espacial é indissociável aos problemas socioeconômicos. Enquanto as características socioeconômicas representam a forma como a renda é distribuída, o padrão espacial é centrado na distribuição territorial desigual das atividades produtivas. Assim, forma, os desdobramentos da estrutura socioeconômica e espacial podem servir de elementos para amenizar as desigualdades, mediante um quadro que obstaculiza a formação de mercado interno em espaços outros que não sejam aqueles que já detêm vantagens locacionais (LIMA; SILVA; LIMA, 2016).

A partir da década de 1970, a visão dominante na análise do desenvolvimento regional brasileiro considera ter entrado em vigor um processo convergente de desenvolvimento, onde as diferenças inter-regionais reduziram gradualmente. Esse processo ficou conhecido na literatura especializada como desconcentração espacial da atividade econômica ou reversão da

DRd - Desenvolvimento Regional em debate (ISSNe 2237-9029) 
polarização dos centros industriais dominantes ${ }^{4}$. Em nível nacional, essa noção se refere à perda de espaço da economia paulista, havendo dessa forma, uma distribuição do desenvolvimento econômico para novas regiões, até então isoladas, ou para regiões pobres como o Nordeste brasileiro (RIBEIRO; PÔRTO JUNIOR, 2003; CANO, 2008).

No Ceará, a partir de meados da década de 1980, implanta-se um novo modo de conceber e executar políticas econômicas. A nova estratégia de desenvolvimento passa a envolver medidas de saneamento da máquina estatal, forte contenção dos gastos públicos, redução do número de pessoal, além de uma política de incentivos fiscais e investimentos em infraestrutura (VALOIS; ALVES, 2006). De acordo com a visão governamental, tais mudanças ajudariam a definir os rumos e perspectivas do Ceará no século XXI, portanto incorporando uma ideia de planejamento de longo prazo (PARENTE; ARRUDA, 2002).

O Governo das Mudanças ou Era Jereissati teve como prioridade administrativa a execução de projetos estruturantes. Tais projetos envolvem diversas áreas importantes, como: reestruturação da economia rural, com ênfase na agricultura irrigada e na agroindústria; interiorização do desenvolvimento industrial, com projetos na área de recursos hídricos, investimento em infraestrutura urbana e institucional, implantação do Complexo Industrial do Pecém, que inclui a construção de um porto, a $70 \mathrm{~km}$ de Fortaleza, uma siderúrgica e instalação de um polo metal-mecânico; investimentos na área do turismo, estradas, energia, educação básica, moradia, combate a pobreza, qualificação e geração de empregos, cultura e transportes (PARENTE; ARRUDA, 2002).

No entanto, os resultados dessa reestruturação produtiva apontam para a seletividade das formas de apropriação espacial das atividades econômicas sobre a rede urbana do Ceará (LIMA JÚNIOR, 2014). Conforme Lima, Silva e Lima (2016), a literatura identifica vários argumentos capazes de justificar a especialização e concentração das atividades econômicas. Alguns dos aspectos mais gerais presentes em diversas análises para explicar a especialização locacional das atividades, são: as vantagens comparativas, a presença das economias de escala, e economias externas ou externalidades marshallianas.

Diniz e Lemos (1990) apud Lima, Silva e Lima (2016), elencam três fatores decisivos na explicação da configuração espacial de atividades econômicas: o papel interventor do Estado na economia, o desempenho dos recursos naturais e os fatores espaciais, tais como os diferentes níveis de recursos que permitem a diversificação das atividades.

A problemática desse trabalho é investigar a relação das ocupações nas mesorregiões do Ceará, conforme a concentração espacial das atividades econômicas. Para tanto, seu objetivo geral foi analisar os quocientes locacionais das mesorregiões cearenses, nos anos de 2005 e 2015. Especificamente, objetivou-se fazer uma breve revisão de literatura sobre o conceito de região, teorias de desenvolvimento regional e a utilização de indicadores locacionais no estudo do desenvolvimento regional.

Como forma de alcançar o objetivo, utilizou-se o Quociente Locacional como medida de localização. Conforme Alves (2012), as medidas de localização se referem à natureza setorial entre as distintas regiões, e se concentram na localização espacial das atividades econômicas e nas mudanças ao longo do tempo, bem como nos padrões de concentração ou dispersão espacial dessas atividades. Portanto, justifica-se a realização deste estudo, sem

${ }^{4}$ Para um aprofundamento deste processo consultar obras de Cano (2008), Diniz (1993), Pacheco (1998). 
dúvida, pela relevância de se analisar a concentração ou distribuição espacial das atividades econômicas entre as mesorregiões do Ceará.

Dessa forma, algumas indagações que problematizam o trabalho são: existe concentração espacial de atividades econômicas nas mesorregiões cearenses? E, se sim, em quais mesorregiões estão concentradas essas atividades?

Como hipótese a estes questionamentos está a assertiva de que existe concentração da atividade Industrial e Construção Civil na Mesorregião Metropolitana de Fortaleza, visto que, historicamente, é a região que mais se destaca nesses setores. De que a Agropecuária, esteja concentrada nas mesorregiões onde se encontram os Agropolos e as políticas de Modernização Agrícola. E, que os setores de Serviços e comércio estejam distribuídos por todas as mesorregiões.

Além desta introdução, a construção feita está estruturada numa breve revisão de literatura abordando o conceito de região, as principais teorias do desenvolvimento regional, bem como a técnica de indicadores locacionais para o estudo do desenvolvimento regional, seguido por a apresentação da metodologia, da análise dos resultados e por fim, as considerações finais.

\section{REVISÃO DE LITERATURA}

\subsection{CONCEITO DE REGIÃO}

O estudo sobre dinâmica regional requer a definição preliminar do conceito de região para evitar imprecisões sobre o próprio objeto de estudo. Diante disso, a utilização do conceito de uma região econômica é justificada pela hipótese de que uma região cresce ou declina como um todo, ao invés de ter modificações de renda como a soma aleatória de variações independentes nas atividades nela localizadas. No entanto, cabe destacar que qualquer que seja o critério adotado, ele vai implicar em um corte arbitrário, visto que no sistema capitalista o espaço econômico é tendenciosamente integrado e articulado (LIMA; SIMÕES, 2009). Parte dos estudos considerados como clássicos iniciais acerca dos estudos sobre região nasce das contribuições do pensamento francês, dentre elas o pensamento de Vidal de La Blache, que procurava definições a partir de atributos naturais e humanos (GRIGG, 1974).

Nas investigações brasileiras, Haesbaert (1988) concebe que a região pode ser conceituada como um espaço de identidade ideológico cultural e representatividade política, que se articula em função de interesses específicos, comumente econômicos, por uma função ou bloco regional de classe que nele reconhece sua base territorial de reprodução.

Gomes (2000), em seus estudos sobre essa temática, identificou três conceitos em que a noção de espaço ao delimitar o conceito de região vem sendo construída: o domínio do senso comum, o domínio da administração e o domínio científico. Na linguagem cotidiana do

DRd - Desenvolvimento Regional em debate (ISSNe 2237-9029) 
senso comum, a noção de região parece estar relacionada a dois princípios fundamentais: o de localização e o de extensão. No que diz respeito ao domínio administrativo, a noção de região tem sido utilizada no sentido de delimitação de limites e hierarquias administrativas, ou seja, vista como uma unidade administrativa e, neste caso, a divisão regional é o meio pelo qual se exerce frequentemente a hierarquia e o controle na administração dos Estados. Por sua vez, no que se refere ao domínio científico, nas ciências em geral, como na matemática, biologia, geologia e etc., a noção de região possui o emprego também associado à localização de certo domínio de determinados fenômenos.

Para Souza (2009), uma região é como um ponto abstrato. Desse modo, ela forma sua identidade com as características que lhe são próprias. Apresenta-se como um campo de forças que atrai unidades econômicas e organiza todo o território à sua proximidade. Ainda que não exista uma definição precisa para o termo, há três tipos de região: homogênea, que se caracteriza pela semelhança de suas unidades componentes, como topografia, relevo, tipo de solo, clima e características econômicas; polarizada, determinada mediante um polo urbanoindustrial que organiza a sua área de influência; e região-plano, que, homogênea ou polarizada, está afetada por um problema específico, como seca ou nível de pobreza.

A palavra região apresenta três dificuldades com relação ao seu conceito: a primeira reside na delimitação precisa das fronteiras regionais, que não coincidem, necessariamente, com as fronteiras administrativas adotadas pelo setor público; a segunda é a restrição da contiguidade, em que o território regional deve ser contínuo e não intercalado pelo território de outras regiões; e a terceira diz respeito à sua dinâmica econômica (SOUZA, 2009).

De acordo com Lima e Esperidião (2014), a ideia de região vem perdendo importância e dando lugar a uma noção mais neutra de espaço. Isso porque o espaço econômico de um determinado polo urbano-industrial normalmente ultrapassa as fronteiras regionais e adquire uma conotação dinâmica.

Lopes (2001) afirma que as localizações no espaço condicionam o desenvolvimento e este se condiciona pelas localizações. Nesse sentido, há recursos naturais e recursos humanos perfeitamente localizados. Há, no entanto, atividades cuja localização deve ser mais racional e o aproveitamento dos recursos, na distribuição de benefícios para as populações, mais elevado. Assim, as regiões não podem ser consideradas fins em si mesmas, mas meios para atingir os fins, razão pela qual se espera que o conceito de região resulte dos seus próprios objetivos.

\subsection{TEORIAS DE DESENVOLVIMENTO REGIONAL}

O desenvolvimento deve ser encarado como um processo complexo de mudanças e transformações de ordem econômica, política e, principalmente, humana e social. Dessa forma, desenvolvimento nada mais é que o crescimento, incrementos positivos no produto e na renda, transformado para satisfazer as mais diversificadas necessidades do ser humano, tais como: saúde, educação, habitação, transporte, alimentação, lazer, dentre outras (OLIVEIRA, 2002). A elevação qualitativa dos níveis de vida é o resultado mais pujante neste processo.

DRd - Desenvolvimento Regional em debate (ISSNe 2237-9029) 
No entanto, o processo de desenvolvimento ocorre de maneira desigual e assincrônico em várias partes. Ou seja, é um processo bastante irregular e, que uma vez iniciado em determinados pontos, possui a característica de fortalecer áreas/regiões mais dinâmicas e que apresentam maior potencial de crescimento. Dessa forma, a dinâmica econômica regional torna-se objeto de estudo bastante complexo, dadas as inter-relações existentes dentro e entre diferentes localidades e sua importância para a coesão da economia nacional (LIMA; SIMÕES, 2009).

As teorias tradicionais sobre desenvolvimento regional, normalmente, denotam a ideia da existência de uma força motriz de caráter exógeno capaz de influenciar, através de encadeamentos, as demais atividades econômicas. De forma geral, é o paradigma "centroabaixo" devido à presença de forças impulsoras originadas das regiões centrais. Nesta definição enquadram-se a Teoria da Base de Exportação, Teoria da Difusão e a Teoria do Polo de Crescimento (OLIVEIRA; LIMA, 2003).

A Teoria da Base de Exportação (TBE), desenvolvida por Douglas North, tinha por objetivo explicar o desenvolvimento de determinada região, como um processo que tem sua origem ligada a um impulso externo, ou seja, a demanda de seus produtos por outras regiões ou países, onde as exportações, através do efeito multiplicador, geram o desenvolvimento econômico da região em análise (LIMA et al., 2013).

Na Teoria da Difusão, o desenvolvimento se dá com a industrialização e com a concentração das atividades em reduzido número de grandes centros urbanos de onde são irradiados efeitos, ou melhor, encadeamentos capazes de dinamizar a economia das demais regiões (OLIVEIRA; LIMA, 2003).

De acordo com Souza (1993), um Polo de Crescimento é um complexo industrial localizado, formado por atividades interdependentes, que possui em seu meio, no mínimo, uma indústria motriz. Em razão da distribuição geográfica dos efeitos de encadeamento e da abrangência podem ser polos locais, regionais, nacionais e internacionais. Um Polo de Desenvolvimento é um Polo de Crescimento que provoca efeitos dinâmicos capaz de gerar mudanças estruturais no local que está implantado, e transbordar efeitos de encadeamento para outras áreas.

A partir das teorias citadas é possível verificar que o desenvolvimento das atividades no espaço tem um papel importante ligado ao sucesso ou atraso de uma região, inclusive possibilitando que uma determinada área possa ser qualificada como um polo industrial, por exemplo. Dessa forma é fundamental a escolha da localização das atividades econômicas e abordar questões sobre a proximidade das matérias-primas, redução dos custos de produção, custos com transportes, aumento dos lucros, entre outros fatores (LIMA et al., 2013).

Nos últimos anos as teorias de desenvolvimento regional sofreram grandes transformações, de um lado provocadas pela crise e pelo declínio de muitas regiões tradicionalmente industriais e, de outro, pela emergência de regiões portadoras de novos paradigmas industriais. Esse fenômeno está associado às mudanças radicais nas formas e nos modos de produção e de organização industriais, bem como à globalização e à abertura das economias nacionais. O que se pode observar, desde o fim da década de 1980, é que, ao mesmo tempo em que ocorre um movimento de extroversão por parte das empresas (subcontratações, alianças e fusões) e dos países (abertura comercial e aumento do volume do 
capital em circulação mundial), as regiões no interior dos países vêm mostrando um movimento de endogeneização, tanto das decisões relacionadas ao seu destino quanto do uso dos meios e dos recursos utilizados no processo econômico. Isso mostra que a organização territorial deixou de ter um papel passivo para exercer um papel ativo diante da organização industrial (AMARAL FILHO, 2001).

Dessa maneira, é possível analisar o desenvolvimento regional a partir de uma perspectiva endógena, ou seja, dando ênfase nos fatores internos à região capazes de transformar um impulso externo de crescimento econômico em desenvolvimento para toda sociedade. É o chamado paradigma "desde baixo", este paradigma aponta a necessidade de as políticas macroeconômicas privilegiarem os elementos locais para promover $\mathrm{o}$ desenvolvimento, visando ao aproveitamento pleno dos recursos humanos, ambientais e institucionais da região (OLIVEIRA; LIMA, 2003).

\subsection{A UTILIZAÇÃO DE INDICADORES LOCACIONAIS PARA O ESTUDO DO DESENVOLVIMENTO REGIONAL}

Medidas de localização referem-se à natureza setorial entre as distintas regiões, bem como na determinação das especializações das mesmas. Elas se concentram na localização espacial das atividades econômicas e nas mudanças espaciais ao longo do tempo, bem como nos padrões de concentração ou dispersão espacial dessas atividades (ALVES, 2012).

Cada vez mais as teorias de localização vêm ganhando importância, auxiliando no entendimento e na identificação das disparidades regionais mostrando quais regiões necessitam de maior atenção. Dessa forma, a localização das atividades econômicas exerce, cada vez mais, influência no desenvolvimento regional, conhecendo a estrutura setorialprodutiva e verificando as transformações dessa estrutura no decorrer do tempo, capaz de impactar seu padrão de crescimento e desenvolvimento (RAMOS et al., 2017).

A literatura referente ao desenvolvimento regional demonstra que vários estudos tiveram a iniciativa de analisar essa questão em diversos âmbitos territoriais, desde uma microrregião em determinado estado a unidade nacional, por meio da utilização de indicadores locacionais. Dentre esses, os trabalhos de Querer e Moraes (2012), Lima e Esperidião (2014), Gonçalves e Cardoso (2015), Lima, Silva e Lima (2016), Ramos et al., (2017), Mattei e Mattei (2017), Frete et al., (2018), Valdo et al., (2018) e Fagundes, Oliveira e Dias (2018).

Querer e Moraes (2012) investigaram a relação das ocupações nas mesorregiões do Rio Grande do Sul, conforme a concentração espacial em determinados espaços. O objetivo do estudo foi identificar quais as mesorregiões são especializadas em setores dinâmicos e quais são voltadas para os setores tradicionais. Para atingir os objetivos do estudo foram utilizados o Quociente Locacional e o Coeficiente de Localização. Os resultados da pesquisa apontaram para a concentração de atividades consideradas dinâmicas em determinadas mesorregiões. As mesorregiões Sudeste e Sudoeste mostraram-se especializadas em setores não dinâmicos, enquanto as demais foram especializadas em pelo menos um setor dinâmico, exceto a mesorregião Metropolitana, a qual se apresentou como uma região diversificada.

DRd - Desenvolvimento Regional em debate (ISSNe 2237-9029) 
$\mathrm{Na}$ pesquisa de Lima e Esperidião (2014), o objetivo foi analisar o Quociente Locacional das regiões brasileiras nos anos de 1991, 2000 e 2010. Nesse estudo foi utilizado apenas o Quociente Locacional como indicador locacional. De acordo com os resultados da pesquisa constatou-se que nas regiões Norte, Nordeste e Centro-Oeste, nos referidos anos, o setor de serviços apresentou QL.>1, indicando a especialização dessas regiões em pelo menos uma atividade econômica. Em 2010, o agronegócio apresentou um QL>2, no Centro-Oeste, o que indica uma tendência de diversificação. Com base nos índices locacionais, concluiu-se que o setor de serviços vem mostrando um alto grau de especialização nas regiões e demonstra ser o mais significativo entre os estados e regiões brasileiras.

Gonçalves e Cardoso (2015) desenvolveram uma investigação dos arranjos produtivos locais de Portugal, com o objetivo de buscar evidências dos efeitos aglomerativos e de especialização nas regiões portuguesas. Na pesquisa foram utilizados dados do emprego em dez ramos de atividades distintos, para o ano de 2010, para os quais foram calculados indicadores de especialização e localização, como Quociente Locacional (QL), Coeficiente de Localização (CL) e Coeficiente de Especialização (CE). O estudo concluiu que há vantagem aglomerativa no corredor costeiro Porto-Lisboa e na região em torno da Serra da Estrela, além de uma distribuição do emprego com algum nível de localização, mas ao mesmo tempo bem distribuída quando comparada com Portugal como um todo.

Já Lima; Silva e Lima (2016) buscaram analisar a dinâmica espacial da indústria nas mesorregiões do Rio Grande do Norte, nos anos 2004 e 2014. Semelhante a Lima e Esperidião (2014), neste estudo também foi utilizado apenas o Quociente Locacional. De acordo com os resultados da pesquisa o perfil industrial do Rio Grande do Norte é caracterizado pela predominância de setores menos dinâmicos e uma tendência de concentração espacial. Há uma acentuada concentração econômica na mesorregião Leste Potiguar, que também é caracterizada pela presença da Região Metropolitana de Natal (RM Natal), onde está a capital do estado. Ademais, 62\% dos empregos industriais gerados no ano de 2014 estavam concentrados na referida mesorregião, com destaque para a atividade de Construção Civil. A segunda mesorregião que mais participou na geração de emprego foi a Oeste Potiguar, respondendo por $20 \%$, e também teve a atividade da Construção Civil como a mais representativa. A Central Potiguar e a Agreste responderam por $13 \%$ e 5\%, respectivamente, dos empregos formais das atividades industriais. Em suma, os resultados alcançados reiteram a importância de políticas que priorizem uma maior desconcentração produtiva, favorecendo uma interiorização da economia.

Por sua vez, Ramos et al., (2017), analisaram a dinâmica regional das atividades produtivas na microrregião de Porto Nacional, estado do Tocantins, nos anos de 2005, 2010 e 2015. Para alcançar seus objetivos foram utilizados o Quociente de Localização e o Índice de Concentração de Hirschman-Herfindahl (IHH). De acordo com os resultados da pesquisa a dinâmica regional das atividades produtivas na microrregião em estudo se localizam em áreas mais desenvolvidas como na capital e ao seu entorno, e apresentam concentração e especialização maior no setor da administração pública e principalmente na agropecuária.

Mattei e Mattei (2017) avaliaram a especialização e concentração de atividades e analisaram as mudanças na distribuição dos setores econômicos e na estrutura produtiva nos três estados da Região Sul do Brasil nos anos de 2010 e 2015 a partir do emprego formal obtidos na Relação Anual de Informações Sociais (RAIS). Para cumprir tais objetivos foram utilizados o Quociente Locacional para avaliar a especialização, o Coeficiente de Localização 
para determinar a concentração, o Coeficiente de Redistribuição para detectar a mudança da distribuição dos setores no tempo e o Coeficiente de Redistribuição para avaliar a mudança na estrutura produtiva. De acordo com os resultados da pesquisa o estado do Paraná se destacava na especialização na agropecuária, o Rio Grande do Sul na administração pública e serviços industriais, e Santa Catarina no extrativismo mineral e indústrias de transformação. O coeficiente de localização indicou não haver um padrão de concentração de nenhuma atividade, o coeficiente de redistribuição indicou que não houve mudanças no padrão espacial de localização das atividades de 2010 para 2015 e o coeficiente de reestruturação mostrou que os três estados não apresentaram mudanças na sua estrutura produtiva de 2010 para 2015.

Outro estudo que utiliza indicadores regionais é o de Firetti et al., (2018). Os autores identificam e localizam sistemas locais de produção agropecuária relevantes regionalmente no Estado de São Paulo trazendo informações sobre a concentração e especialização de 63 atividades em 40 microrregiões formadas pelos Escritórios de Desenvolvimento Rural da Secretaria Estadual de Agricultura e Abastecimento. Os métodos utilizados foram os índices de Gini locacional e Quociente Locacional. De acordo com os resultados da pesquisa, estes apontam elevados índices de concentração espacial do valor da produção da agropecuária paulista, exceto da Cana-de-açúcar; Carne-bovina; Leite resfriado e Milho. Observou-se em diferentes grupos de produtos (animais, grãos e fibras, olerícolas, frutas frescas e industriais) a especialização local para 33 produtos, que apesentaram GL acima de 0,81 e QL variando de 2,0 a 77,03 .

$\mathrm{Na}$ busca de analisar a concentração e a especialização da produção de leite nas microrregiões do Estado de São Paulo, no ano de 2015, Valdo et al., (2018) utilizaram os métodos do cálculo do Quociente Locacional (QL) e do Gini Locacional (GL) das produções leiteiras, utilizando-se as variáveis relacionadas ao valor da produção em 40 microrregiões do estado. O cálculo de GL resultou em 0,466 enquanto que apenas seis microrregiões foram caracterizadas como especializadas: Guaratinguetá (11,79); Pindamonhangaba $(6,95)$; Presidente Venceslau (3,76); Fernandópolis $(2,40)$; General Salgado (2,25); e Bragança Paulista $(2,22)$.

Já Fagundes; Oliveira e Dias (2018) analisaram o nível de concentração das principais atividades pecuárias do Mato Grosso do Sul e identificaram os aspectos relevantes do desenvolvimento dessas atividades. Para tanto, foi utilizado o método quantitativo para identificar e mensurar os indicadores de especialização que compõem o Índice de Concentração Normalizado (ICN), a fim de que possam ser identificados os municípios que possuem contração em nível de emprego nos municípios do Mato Grosso do Sul. O ICN foi aplicado nas atividades referentes a bovinocultura, avicultura e suinocultura. A abordagem quantitativa ainda utiliza os índices de especialização sendo eles: Quociente Locacional (QL); o Índice de Hirschman e Herfindahl Modificado (IHHM); e o Índice de Participação Relativa (PR), que dos quais formam o ICN. Os resultados identificaram que a bovinocultura possui uma grande expressividade na estrutura econômica do estado, por sua vez, a avicultura e suinocultura, apesar de não ter a mesma contribuição que a bovinocultura em termos de quantidade ofertada, essas atividades estão em grande expansão no estado do Mato Grosso do Sul.

DRd - Desenvolvimento Regional em debate (ISSNe 2237-9029) 


\section{METODOLOGIA}

Este estudo tem abordagem teórico-quantitativa caracterizado como exploratório. O trabalho foi realizado utilizando-se o método de análise através do Quociente Locacional. Optou-se pela utilização do recorte das mesorregiões em função das informações disponíveis, através das quais se podem identificar os diferentes espaços cearenses, bem como, sua dinâmica.

O período analisado corresponde aos anos de 2005 e 2015. Estes anos foram definidos por corresponder a um longo período onde se consegue uma significativa avaliação das transformações ocorridas, aumentando o nível de confiança dos resultados.

Os dados básicos utilizados para a construção dos indicadores referem-se aos empregos formais classificados por setores entre as mesorregiões do estado do Ceará. Estas informações correspondem aos anos de 2005 e de 2015, e foram obtidas na RAIS (Relação de Anual de Informações Sociais), mantido pelo MTE (Ministério do Trabalho e Emprego).

\section{1 ÁREA DE ESTUDO}

O Estado do Ceará possui uma área total de 148.886,3 km², situando-se na Região Nordeste do Brasil, tendo como Estados limítrofes o Piauí a Oeste, o Rio Grande do Norte e a Paraíba a Leste, Pernambuco ao Sul e o Oceano Atlântico ao Norte. Possui localização estratégica devido a sua proximidade com a Europa, América do Norte e ainda com o Continente Africano, garantindo grande fluxo turístico internacional e boas condições para o desenvolvimento do comércio exterior (IPECE, 2016).

No tocante à divisão político-administrativa, o Ceará é composto por 184 municípios, 33 Microrregiões Administrativas e 7 mesorregiões (IPECE, 2016). Para a análise da dinâmica espacial dos setores econômicos do Ceará no período de 2005 a 2015, tomou-se como unidade básica de estudo as mesorregiões que são elas: Noroeste Cearense, Norte Cearense, Metropolitana de Fortaleza, Sertões Cearenses, Jaguaribe, Centro-Sul Cearense e Sul Cearense.

Em termos populacionais, a Tabela 1 apresenta as populações urbana, rural e total destas 7 mesorregiões do Ceará. Se destacam como mais populosas as Mesorregiões de localização litorânea que além da Metropolitana de Fortaleza são a Norte e Noroeste Cearenses. 
Tabela 1 - População Urbana, Rural e total das Mesorregiões Cearenses (2010).

\begin{tabular}{cccc}
\hline Mesorregiões & Urbana & Rural & Total \\
\hline Centro-Sul Cearense & 227.667 & 148.572 & 376.239 \\
Jaguaribe & 308.245 & 220.029 & 528.274 \\
Metropolitana de Fortaleza & 3.367 .714 & 100.423 & 3.468 .137 \\
Noroeste Cearense & 787.722 & 539.049 & 1.326 .771 \\
Norte Cearense & 560.520 & 446.062 & 1.006 .582 \\
Sertões Cearenses & 476.210 & 393.568 & 869.778 \\
Sul Cearense & 618.479 & 258.121 & 876.600 \\
\hline TOTAL & $\mathbf{6 . 3 4 6 . 5 5 7}$ & $\mathbf{2 . 1 0 5 . 8 2 4}$ & $\mathbf{8 . 4 5 2 . 3 8 1}$ \\
\hline
\end{tabular}

Fonte: Elaboração própria a partir dos Censos de 2010.

\subsection{MÉTODO DE ANÁLISE REGIONAL}

O Quociente Locacional é considerado a medida mais difundida em pesquisas que têm como escopo identificar a estrutura produtiva e potencial desenvolvimento das regiões. Essa é também a medida mais difundida na literatura da área econômica. A principal ideia é a de que o indicador das potencialidades de desenvolvimento econômico de uma região é o que já existe, ou seja, a sua especialização atual (RIEDL; MAIA, 2007).

De acordo com Scherer e Moraes (2012), a análise locacional tem como objetivo eliminar as perturbações estatísticas oriundas dos estudos de regiões de tamanhos diferentes. Nessa análise, utilizam-se valores relativos cujo índice é o Quociente Locacional. O QL indica a concentração relativa de determinado setor da atividade produtiva em uma região, após comparação com outras regiões. Quanto maior o QL, maior a especialização da região no referido ramo.

O QL poderá ser verificado com base em ramos específicos ou em seu conjunto. Segundo Scherer e Moraes (2012), determina-se o QL por meio da fórmula (1):

$$
Q L i j=\frac{E i j / \sum_{j} E i j}{\sum_{i} E i j / \sum i \sum j E i j}
$$

Onde:

$E i j=$ emprego formal do setor "i”" da mesorregião “j”;

$\sum i E i j=$ emprego formal em todos os setores da mesorregião “j”;

$\Sigma j E i j=$ emprego formal do setor "i" em todas as mesorregiões;

$\sum i \Sigma j E i j=$ emprego formal de todos os setores de todas as mesorregiões.

Desse modo, os resultados da análise locacional têm os seguintes significados:

QL $>1$, a concentração do setor i na unidade territorial j será maior que a concentração na própria unidade de referência; 
$\mathrm{QL}=1$, a concentração do setor i na unidade territorial $\mathrm{j}$ é igual à concentração desse setor na unidade de referência, ou seja, a participação do setor na região é igual à participação nas regiões como um todo;

$\mathrm{QL}<1$, o setor i não está relativamente concentrado na unidade territorial $\mathrm{j}$.

Os índices mostram um processo de especialização ou diversificação da estrutura produtiva no período analisado. Ou seja, indica a especialização relativa de dada região geográfica em determinado setor produtivo, comparativamente ao grau de concentração do mesmo setor na região como um todo (GUALDA et al., 2005).

\section{ANÁLISE DE RESULTADOS}

Conforme se pode observar, a partir da Tabela 02, a agropecuária tem significativa representatividade na geração de postos formais de trabalho nas mesorregiões do Noroeste Cearense, Jaguaribe e Norte Cearense, sendo seu maior destaque constatado na Mesorregião do Jaguaribe $(8,43)$. O principal expoente desse resultado está na fruticultura irrigada.

De acordo com Lima Junior (2014), com a criação dos polos de modernização agrícola, as principais regiões focalizadas foram: o Médio Vale do Rio Jaguaribe (na Mesorregião Jaguaribe), o Vale do Rio Acaraú (na Mesorregião Noroeste Cearense), as áreas úmidas das Serras da Ibiapaba (também na Mesorregião Noroeste) e Serra de Baturité (na Mesorregião Norte). O foco principal foi a inserção internacional pela oferta de frutas, os estímulos ao agronegócio com ênfase na fruticultura irrigada ganha o seu maior destaque na Mesorregião Jaguaribe, onde despontou o mais importante polo de produção de frutas para exportação do estado e se apresenta como uma das áreas rurais mais dinâmicas do Ceará.

No entanto, diferente da Mesorregião do Jaguaribe que é especializada no setor agropecuário, as Mesorregiões Norte e Noroeste Cearense são consideradas diversificadas, com forte presença tanto no setor agropecuário quanto no industrial e de serviços.

Tabela 2 - Quociente Locacional das Mesorregiões Cearenses em 2005

\begin{tabular}{cccccc}
\hline Mesorregiões & Agropecuária & Comércio & Construção Civil & Indústria & Serviços \\
\hline Noroeste Cearense & $\mathbf{1 , 2 8}$ & 0,61 & 0,26 & $\mathbf{1 , 2 7}$ & $\mathbf{1 , 0 3}$ \\
Norte Cearense & $\mathbf{2 , 6 9}$ & 0,47 & 0,35 & $\mathbf{1 , 1 6}$ & $\mathbf{1 , 0 4}$ \\
Metropolitana de Fortaleza & 0,41 & $\mathbf{1 , 0 9}$ & $\mathbf{1 , 2 5}$ & $\mathbf{1 , 0 1}$ & 0,98 \\
Sertões Cearenses & 0,56 & 0,79 & 0,72 & 0,26 & $\mathbf{1 , 3 4}$ \\
Jaguaribe & $\mathbf{8 , 4 3}$ & 0,69 & 0,89 & 0,93 & 0,82 \\
Centro-Sul Cearense & 0,25 & $\mathbf{1 , 1 6}$ & 0,38 & 0,66 & $\mathbf{1 , 1 4}$ \\
Sul Cearense & 0,27 & $\mathbf{1 , 4 0}$ & 0,56 & $\mathbf{1 , 0 2}$ & 0,95 \\
\hline
\end{tabular}

Fonte: Elaboração própria com base nos resultados.

DRd - Desenvolvimento Regional em debate (ISSNe 2237-9029) 
Assim como as Mesorregiões Norte e Noroeste Cearenses, a Mesorregião Metropolitana de Fortaleza apresentou QL $>1$ no ramo de indústria. Essas mesorregiões são concentradoras da atividade industrial em decorrência da seletividade territorial da acumulação que tem no Ceará o apoio dos programas de incentivo à indústria (LIMA JUNIOR, 2014). A Mesorregião Metropolitana apresenta ainda QL> na Construção Civil, setor ligado a Indústria e também no Comercio.

A Mesorregião Sertões Cearenses apresentou QL>1 apenas no ramo de Serviços, o que demonstra um alto grau de especialização desse setor na mesorregião. De fato, esta mesorregião tem influência dos setores da Administração Pública como importantes na definição de suas dinâmicas. Por sua vez, a Mesorregião Centro-Sul Cearense apresentou QL>1 nos ramos de Comércio e Serviços.

Como apontam os resultados dos Quocientes Locacionais no ano de 2015 (Tabela 3), as mesorregiões apresentaram algumas alterações nos setores analisados. A Mesorregião Jaguaribe continuou com destaque no setor agropecuário e apresentou QL dos mais elevados, verificando-se que o Jaguaribe se apresenta importante no universo estadual, para o setor de atividade econômica reforçando seu papel na produção de fruticultura para exportação. Neste contexto, sua principal cultura é o melão, seguido por melancia e manga (SECEX, 2017). Ademais a mesorregião também apresentou $\mathrm{QL}>1$ no ramo da indústria. A participação na indústria se constituiu por meio de plataforma de ação da indústria calçadista subvencionada, com o município de Russas recebendo uma das maiores fábricas no setor (PEREIRA JÚNIOR, 2012).

Tabela 3 - Quociente Locacional das Mesorregiões Cearenses - 2015.

\begin{tabular}{cccccc}
\hline Mesorregiões & Agropecuária & Comércio & $\begin{array}{c}\text { Construção } \\
\text { Civil }\end{array}$ & Indústria & Serviços \\
\hline Noroeste Cearense & $\mathbf{1 , 6 1}$ & 0,85 & 0,39 & $\mathbf{1 , 3 1}$ & 0,99 \\
Norte Cearense & $\mathbf{2 , 2 7}$ & 0,69 & $\mathbf{1 , 0 2}$ & $\mathbf{1 , 3 1}$ & 0,96 \\
Metropolitana de Fortaleza & 0,36 & $\mathbf{1 , 0 2}$ & $\mathbf{1 , 1 9}$ & 0,95 & $\mathbf{1 , 0 1}$ \\
Sertões Cearenses & 0,81 & $\mathbf{1 , 0 2}$ & 0,33 & 0,45 & $\mathbf{1 , 2 2}$ \\
Jaguaribe & $\mathbf{9 , 7 1}$ & 0,96 & 0,39 & $\mathbf{1 , 1 8}$ & 0,75 \\
Centro-Sul Cearense & 0,46 & $\mathbf{1 , 2 5}$ & 0,29 & 0,87 & $\mathbf{1 , 0 4}$ \\
Sul Cearense & 0,51 & $\mathbf{1 , 2 2}$ & 0,83 & $\mathbf{1 , 0 4}$ & 0,95 \\
\hline
\end{tabular}

Fonte: Elaboração própria com base nos resultados.

A Mesorregião Metropolitana de Fortaleza manteve-se com QL $>1$ nos setores de Comercio e Construção Civil. No entanto, apresentou modificações em outros setores, perdendo concentração no ramo da Indústria e ganhando espaço no setor de Serviços. Essa perda na concentração no setor industrial é explicada pelo direcionamento da indústria para as proximidades da região, dentre elas o caso do Complexo Industrial e Portuário do Pecém que tem localização no município de São Gonçalo do Amarante.

É importante relativizar em termos espaciais tendo em vista as diferenças de divisões entre o conjunto que compõe a Mesorregião Metropolitana e a Região Metropolitana de Fortaleza (RMF). Uma parte dos municípios da Mesorregião Norte Cearense que foram

DRd - Desenvolvimento Regional em debate (ISSNe 2237-9029) 
beneficiados com a implantação de empreendimentos incentivados está inserida na RMF, entre eles, o município de São Gonçalo do Amarante que, em decorrência da implantação do CIPP, recebeu 30 empresas incentivadas (SDE, 2010).

A Mesorregião Sul Cearense manteve-se diversificada, com QL $>1$ nos setores de Comercio e Indústria. Na Indústria a mesorregião recebeu importantes empreendimentos incentivados principalmente no ramo de calçados, com localização na conurbação CratoJuazeiro do Norte-Barbalha (LIMA JUNIOR, 2014). Por sua vez a mesorregião Sertões Cearenses diversificou-se apresentando QL $>1$ no ramo de Serviços e de Comércio. As Mesorregiões dos Sertões e Centro Sul continuam sem exibir representatividade dinâmica na atividade industrial.

Os setores de Serviços e de Comércio, que estão interligados se configuram de forma semelhante nas mesorregiões, provavelmente impelidos pelo comercio varejista, dadas pela expansão do consumo popular. Nas Mesorregiões Centro-Sul e Sul Cearense o setor de comercio apresenta o maior resultado. Conforme Lima Junior (2014), no caso da Mesorregião Sul Cearense, isto ocorre como reflexo do papel exercido pelo comercio da conurbação CratoJuazeiro do Norte-Barbalha e pela quantidade de visitantes sazonais, associados às romarias ligadas à figura do Padre Cícero, deixando movimentado o comercio de Juazeiro do Norte.

\section{CONSIDERAÇÕES FINAIS}

O objetivo principal do artigo foi analisar a dinâmica locacional das atividades econômicas no Estado do Ceará a partir de suas mesorregiões, nos anos de 2005 e 2015. Os dados utilizados foram da Relação Anual de Informações Sociais (RAIS) do Ministério do Trabalho e do Emprego (MTE) e o recorte temporal compreendeu os anos de 2005 e de 2015.

A Mesorregião Metropolitana de Fortaleza apresentou desempenho significativo no setor de comércio e construção civil, nos dois anos analisados, demonstrando especialização no setor. Embora tenha diminuído a concentração no setor industrial da mesorregião, cabe destacar que essa reorientação espacial na indústria foi destinada a municípios que compõe a Região Metropolitana de Fortaleza, reafirmando, assim, a apropriação espacial pela reestruturação produtiva.

O fato de a Mesorregião do Jaguaribe ter apresentado os maiores índices de concentração no ramo agropecuário tanto em 2005 quanto 2015 demonstra a influência da fronteira agropecuária nesta região. No entanto, ressalta-se também as Mesorregiões Norte e Noroeste Cearenses que apresentaram concentração no setor agropecuário.

Os setores de Serviços e Comércio apresentaram um alto grau de especialização e foram os mais significativos entre as mesorregiões cearenses nos anos analisados. Por outro lado, o setor de Construção está fortemente concentrado nas Mesorregiões Metropolitana de Fortaleza e Norte Cearense.

Dessa forma, verificam-se as assertivas analisadas nesse estudo, embora a Mesorregião Metropolitana venha perdendo concentração espacial da indústria ainda é a

DRd - Desenvolvimento Regional em debate (ISSNe 2237-9029) 
maior concentradora, assim como do setor de Construção Civil. A Mesorregião do Jaguaribe onde está localizado o Agropolo Baixo Jaguaribe foi a maior concentradora do setor agropecuário, seguida pelas Mesorregiões Norte e Noroeste Cearenses, onde também se localizam agropolos. Por sua vez, os serviços apresentaram a maior distribuição significativa entre as mesorregiões.

\section{REFERÊNCIAS}

ALVES, L. R. Indicador es de Localização, especialização e estruturação regional. In: PIACENTI, C. A.; LIMA, J. F. (Orgs). Análise Regional: metodologia e indicadores. 1.ed. Curitiba, PR: Camões, 2012, p. 35-50.

AMARAL FILHO, J. A endogeneização no desenvolvimento econômico regional e local. Planejamento e Políticas públicas, v. 23, p. 261-286, 2001.

CANO, W. Desconcentração produtiva regional no Brasil (1970-2005). 3.ed. São Paulo: Editora da UNESP, 2008.

DINIZ, Clélio Campolina et al. Desenvolvimento poligonal no Brasil: nem desconcentração, nem contínua polarização. Nova Economia, v. 3, n. 1, p. 35-64, 1993.

FAGUNDES, M. B.; OLIVEIRA, D. V.; DIAS, D. T. Índice de concentração normalizado da pecuária nos municípios de Mato Grosso do Sul. In: Congresso da Sociedade Brasileira de Economia, Administração e Sociologia Rural, 53, 2018. Anais... Campinas, SP: SOBER, 2018.

FIRETTI, R.; VALDO, N. N.; PINATTI, E.; BONACELLI, M. B. Identificação e localização de sistemas locais de produção agrícola no estado de São Paulo. In: Congresso da Sociedade Brasileira de Economia, Administração e Sociologia Rural, 53, 2018. Anais... Campinas, SP: SOBER, 2018.

GRIGG, D. Regiões, modelos e classes. In: CHORLEY, R.; HAGGETT, P. (Org.). Modelos integrados em geografia. São Paulo: Edusp; Rio de Janeiro: LTC Editora, 1974, p. 23-66.

GOMES, P. C. C. O conceito de região e sua discussão. In: CASTRO, I. E.; GOMES, P. C. C.; CORREAA, R. L. (Orgs.). Geografia: conceitos e temas. 2. ed. Rio de Janeiro: Bertrand Brasil, 2000, p. 49-76.

GUALDA, N. L. P. et al.; Identificação das aglomerações industriais no estado do Paraná um estudo exploratório. Revista Brasileira de Economia de Empresas, Brasília, v. 6, n. 1, p. 47-63, 2006.

HAESBAERT, R. Rio Grande do Sul: latifúndio e identidade regional. Porto Alegre: Mercado Aberto, 1988.

DRd - Desenvolvimento Regional em debate (ISSNe 2237-9029) 
IPECE - Instituto de Pesquisa e Estratégia Econômica do Ceará. Ceará em números 2016. Disponível em: < http://www.ipece.ce.gov.br/index.php/ceara-em-numeros $>$. Acesso em: 15 nov. 2017.

LIMA, A. C. C.; SIMÕES, R. F. Teorias do desenvolvimento regional e suas implicações de política econômica no pós-guerra: o caso do Brasil. Belo Horizonte, MG: UFMG/CEDEPLAR, 2009. (Texto para discussão; 358).

LIMA, E. C.; LIMA, E. P. C.; EVAS, I. M.; TEIXEIRA, M. S. G. Base de exportação e sua relação com o desempenho econômico: o caso do estado de Santa Catarina. In: Encontro de Economia Catarinense, 7, 2013. Anais... Florianópolis, SC: APEC, 2013.

LIMA, E. P. C.; SILVA, A. C.; LIMA, E. C. Assimetrias locacionais e padrão industrial: uma análise das mesorregiões do Rio Grande do Norte. In: Encontro Nacional da Associação Brasileira de Estudos Regionais e Urbanos, 14, 2016. Anais... Aracaju, SE: ENABER, 2016.

LIMA, J. K. M.; ESPERIDIÃO, F. Uma análise dos quocientes locacionais das regiões brasileiras nos anos de 1991, 2000 e 2010. Cadernos de Ciências Sociais Aplicadas, Vitória da Conquista, BA, n. 18, p.175-196, 2014.

LIMA JÚNIOR, F. O. Estrutura produtiva e rede urbana no Estado do Ceará durante o período de 1980-2010. Tese (Doutorado em Desenvolvimento Econômico) - Universidade Estadual de Campinas, Campinas, SP, 2014.

LOPES, A. S. Desenvolvimento regional: problemática, teoria, modelos. 5. ed. Lisboa: Fundação Calouste Gulbenkian, 2001.

MATTEI, T. F.; MATTEI, T. S. Métodos de análise regional: um estudo de localização e especialização para a região sul do Brasil. In: Congresso da Sociedade Brasileira de Economia, Administração e Sociologia Rural, 53, 2017. Anais... Santa Maria - RS: SOBER, 2017.

PARENTE, J.; ARRUDA, J. M. A era Jereissati: modernidade e mito. Fortaleza: Edições Demócrito Rocha, 2002. v. 1.

OLIVEIRA, G. B. Uma discussão sobre o conceito de desenvolvimento. Revista da FAE. Curitiba, v. 5, n. 2, p. 37-48, 2002.

; LIMA, J. E. de S. Elementos endógenos do desenvolvimento regional: considerações sobre o papel da sociedade local no processo de desenvolvimento sustentável. Revista da FAE, v. 6, n. 2, p. 29-37, 2003.

PACHECO, C. A. Fragmentação da nação. Campinas: UNICAMP, 1998.

PEREIRA JÚNIOR, E. Território e economia política: uma abordagem a partir do novo processo de industrialização do Ceará. São Paulo: Cultura Acadêmica, 2012.

RAIS - Relação Anual de Informações Sociais. Ministério do Trabalho e Emprego (MTE). RAIS VÍNCULOS. Disponível em: <http://bi.mte.gov.br/bgcaged/rais.php>. Acesso em: 11 nov. 2017. 
RAMOS, M. S. et al. Análise locacional das atividades produtivas na microrregião de Porto Nacional do estado do Tocantins. In: Congresso da Sociedade Brasileira de Economia, Administração e Sociologia Rural, 53, 2015. Anais... Santa Maria, RS: SOBER, 2017.

RIBEIRO, E. P.; PORTO JUNIOR, S. S. Dinâmica Espacial da Renda per Capita e Crescimento entre os Municípios da Região Nordeste do Brasil: uma análise Markoviana. Revista Econômica do Nordeste, Fortaleza, CE, v. 34, n. 3, p. 405-420, 2003.

RIEDL, M.; MAIA, C. M. Especialização e potencial endógeno na análise regional. Revista Brasileira de Gestão e Desenvolvimento Regional, v. 3, n. 2, p. 27-48, 2007.

SCHERER, W. J. G.; MORAES, S. L. Análise locacional das atividades dinâmicas do estado do Rio Grande do Sul. In: Encontro de Economia Gaúcha, 6, 2012. Anais... Porto Alegre, RS: EEG, 2012.

SECRETARIA DE COMÉRCIO EXTERIOR (SECEX). Dados de Exportação do Ceará. Disponível em: $<$ http://portal.siscomex.gov.br/legislacao/orgaos/secretaria-de-comercioexterior-secex>. Acesso em 12 dez. 2017.

SOUZA, N. J. Desenvolvimento polarizado e desequilíbrios regionais no Brasil. Análise Econômica, v. 11, n. 19, p. 29-59, 1993.

SOUZA, N. J. Desenvolvimento regional. São Paulo: Atlas, 2009.

VALDO, N. N.; FIRETTI, R.; PINATTI, E.; BONACELLI, M. B. M. Concentração regional e especialização da produção de leite no estado de São Paulo (2015). In: Congresso da Sociedade Brasileira de Economia, Administração e Sociologia Rural, 53, 2018. Anais... Campinas, SP: SOBER, 2018.

VALOIS, I. S. ALVES, C. L. B. Caracterização do mercado de trabalho na indústria cearense durante a década de 90. In: Encontro Internacional Trabalho e Perspectivas de Formação dos Trabalhadores, 1, 2006. Anais... Fortaleza, CE: LABOR, 2006.

Artigo recebido em: $31 / 08 / 2018$

Artigo aprovado em: 07/12/2018

Artigo publicado em: 04/02/2019 